\title{
Monitoramento Microclimático de Grutas Turísticas em Minas Gerais: Análise Preliminar dos Dados de Temperatura e Umidade Relativa do Ar em Sete Cavernas do Parque Nacional Cavernas do Peruaçu
}

\author{
Mauro Gomes ${ }^{1}$, Darcy Santos ${ }^{1}$, Luiz Travassos ${ }^{2} \&$ Úrsula Ruchkys ${ }^{3}$
}

Recebido em 01/09/2020 - Aceito em 26/03/2021

\footnotetext{
1 Instituto Chico Mendes de Conservação da Biodiversidade/ICMBio, Centro Nacional de Pesquisa e Conservação de Cavernas/CECAV. Brasil. <mauro.gomes@icmbio.gov.br, darcy.santos@icmbio.gov.br>.

2 Pontifícia Universidade Católica de Minas Gerais. Brasil. <luizepanisset@gmail.com>.

3 Universidade Federal de Minas Gerais. Brasil. <tularuchkys@yahoo.com.br>.
}

\begin{abstract}
RESUMO - Os primeiros trabalhos relacionados ao monitoramento climático de cavernas no Brasil são da década de 1960 e foram caracterizados pela baixa densidade amostral (períodos inferiores a um ano) e medições isoladas de temperatura e umidade em cavernas abertas à visitação turística. As pesquisas mais recentes passaram a incorporar novos métodos e tecnologias, como, por exemplo, o uso de registradores automáticos de dados. O Projeto Monitoramento Microclimático de Grutas Turísticas em Minas Gerais pretende realizar um monitoramento de longa duração, previsto para 6 anos, e o presente manuscrito apresentou os resultados da primeira fase do projeto, compreendendo o monitoramento realizado entre os anos de 2017 e 2019 em sete cavernas do Parque Nacional Cavernas do Peruaçu. Para esta análise, foram instalados, no interior e próximo à entrada das cavernas, 41 medidores automatizados, que registraram e armazenaram dados de temperatura $e$ umidade a cada 10 minutos. Os resultados mostram que a caverna Lapa Bonita apresenta a menor temperatura média $\left(20,79^{\circ} \mathrm{C}\right)$ e a Lapa dos Desenhos a maior temperatura média $\left(24,07^{\circ} \mathrm{C}\right)$. Em relação à umidade relativa do ar, a Lapa dos Desenhos apresenta os menores valores, com média de $62,56 \%$ e a Lapa Bonita os maiores, com média de $85,28 \%$ entre todas as cavernas avaliadas e para o período estudado. Os resultados da pesquisa também indicam que, dentre todas as cavernas avaliadas, a Lapa Bonita é aquela que apresenta as menores variações desses parâmetros, com desvio padrão de 0,54 para a temperatura e 9,96 para umidade. O conhecimento das características microclimáticas de cada caverna obtido com os dados do monitoramento pode auxiliar a gestão do parque nacional na adoção de novos limites em relação à capacidade de carga atualmente estabelecida para cada um desses atrativos.
\end{abstract}

Palavras-chave: Espeleoclima; variabilidade meteorológica; Parque Nacional Cavernas do Peruaçu.

\section{Microclimatic Monitoring of Tourist Caves in Minas Gerais: Preliminary Analysis of Temperature and Relative Humidity Data in Seven Caves of the Cavernas do Peruaçu National Park}

\begin{abstract}
In Brazil, the first studies related to cave climate monitoring are from the 1960s and were characterized by low sample density (periods of less than one year) and isolated temperature and humidity measurements in caves open to tourist visitation. The most recent research started to incorporate new methods and technologies, such as, for example, the use of automatic data recorders. The Microclimatic Monitoring of Tourist Caves in Minas Gerais Project intends to carry out long-term monitoring, scheduled for 6 years. This manuscript presented the results of the first phase of the project, comprising the monitoring carried out between 2017 and 2019 in seven caves of the Parque Nacional Cavernas do Peruaçu. For this analysis, 41 automated meters were installed inside and close to entrance to the caves, which recorded and stored temperature and humidity data every 10 minutes. The results show that the Lapa Bonita cave has the lowest average temperature $\left(20.79^{\circ} \mathrm{C}\right)$ and Lapa dos Desenhos, the highest average temperature $\left(24.07^{\circ} \mathrm{C}\right)$. Regarding the relative humidity of the air, Lapa dos Desenhos presents the lowest values, with an average of $62.56 \%$ and Lapa Bonita the highest, with an average of $85.28 \%$ among all the caves evaluated in the period studied. The survey also found that, among all the caves evaluated, Lapa Bonita is the one that show the smallest variations in these parameters, with a standard deviation of 0.54 for temperature and 9.96 for humidity. The
\end{abstract}


knowledge of the microclimate characteristics of each cave obtained with the monitoring data will assist the management of the national park to adopt new limits concerning the load capacity currently established for each of these attractions.

Keywords: Espeleoclimate; meteorological variability; Parque Nacional Cavernas do Peruaçu.

\section{Monitoreo Microclimático de Cuevas Turísticas en Minas Gerais: Análisis Preliminar de Datos de Temperatura y Humedad Relativa en Siete Cuevas del Parque Nacional Cavernas do Peruaçu}

RESUMEN - Los primeros estudios relacionados con el monitoreo climático de cuevas en Brasil son de la década de 1960 y se caracterizaron por una baja densidad de muestra (períodos menos de un año) y mediciones aisladas de temperatura y humedad en cuevas abiertas a la visita turística. Las investigaciones más recientes han comenzado a incorporar nuevos métodos y tecnologías, como, por ejemplo, el uso de registradores de datos automáticos. El Proyecto Monitoreo Microclimático de Cuevas Turísticas en Minas Gerais pretende realizar un monitoreo a largo plazo, programado para 6 años y el presente manuscrito presentó los resultados de la primera fase del proyecto, que comprende el monitoreo realizado entre los años 2017 y 2019 en siete cuevas del Parque Nacional Cavernas do Peruaçu. Para este análisis, se instalaron 41 medidores automáticos en el interior y cerca de la entrada a las cuevas, los cuales registraron y almacenaron datos de temperatura y humedad cada 10 minutos. Los resultados muestran que la cueva Lapa Bonita tiene la temperatura promedio más baja $\left(20,79^{\circ} \mathrm{C}\right)$ y Lapa dos Desenhos la temperatura promedio más alta $\left(24,07^{\circ} \mathrm{C}\right)$. En cuanto a la humedad relativa del aire, Lapa dos Desenhos presenta los valores más bajos, con un promedio de 62,56\% y Lapa Bonita el más alto, con un promedio de $85,28 \%$ entre todas las cuevas evaluadas y para el período estudiado. Los resultados de la encuesta también indican que, entre todas las cuevas evaluadas, Lapa Bonita es la que presenta las variaciones más pequeñas en estos parámetros, con una desviación estándar de 0,54 para temperatura y 9,96 para humedad. El conocimiento de las características micro climáticas de cada cueva obtenido con los datos de monitoreo puede ayudar a la gestión del parque nacional en la adopción de nuevos límites con relación a la capacidad de carga actualmente establecida para cada uno de estos atractivos.

Palabras clave: Espeleoclima; variabilidad meteorológica; Parque Nacional Cavernas do Peruaçu.

\section{Introdução}

Em relação às condições climáticas, uma caverna pode ser considerada como um ambiente homogêneo, que não apresenta variações em relação às oscilações diárias ou sazonais, ou até mesmo com ausência de flutuações meteorológicas. Entretanto, esta percepção de invariabilidade parece ser verdadeira apenas se estas condições forem comparadas com aquelas observadas no ambiente externo (Badino, 2010). Adotando-se uma escala de análise adequada, é possível verificar que ocorrem discretas variações no comportamento microclimático cavernícola que são causadas pelo fluxo de energia e massa existente entre o meio subterrâneo e a superfície (Cigna, 1993). Travassos (2016) destaca que, além da influência da atmosfera externa, fatores intrínsecos das cavernas, tais como topografia, geometria, distribuição espacial das entradas e o fluxo de água subterrâneo exercem influência sobre o microclima cavernícola. Especificamente no que se refere às cavernas turísticas, onde a presença humana é considerada também uma resposta importante às variações microclimáticas ocorridas em seu interior, esse tema vem merecendo destaque nas pesquisas realizadas nesse tipo de ambiente (Cigna, 1993; Pulido-Bosch et al., 1997; Calaforra et al., 2003; Šebela et al., 2013; Šebela \& Turk, 2014; Lobo et al., 2015).

Estudos sistemáticos de monitoramento microclimático em cavernas são realizados há décadas, especialmente no continente europeu. Neste contexto, destacam-se os trabalhos realizados na caverna Postojna, na Eslovênia, onde diversos parâmetros microclimáticos começaram a ser estudados na segunda metade do século XX e permitiram um melhor conhecimento a respeito destas condições e assim contribuíram para a definição de parâmetros de conservação (Šebela et al., 2013). Atualmente, em Postojna, o microclima continua sendo monitorado, especialmente para melhor compreensão da relação entre os possíveis impactos causados pelo uso turístico e a conservação da caverna (Aljančič, 2018). 
Lobo (2010) destaca que as pesquisas sobre o microclima cavernícola no Brasil tiveram início entre as décadas de 1960 e 1980 e foram caracterizadas pela realização de medições pontuais, executadas principalmente por grupos de espeleologia, durante os trabalhos de mapeamento topográfico das cavernas. Com o passar do tempo, houve um considerável avanço nos procedimentos, técnicas e instrumentos utilizados levando este tipo de estudo a adquirir um perfil mais científico, estando atualmente mais associado a projetos desenvolvidos por universidades e pelos centros de pesquisa.

Esses avanços foram impulsionados pelo fortalecimento dos sistemas estaduais e federais de gestão ambiental, que passaram a ser mais exigentes quanto à necessidade de realização de estudos específicos que subsidiassem o adequado manejo de cavernas abertas ao turismo (Lobo, 2010). Neste contexto, destacamos trabalhos que evidenciam a evolução das propostas de monitoramento do microclima de cavernas abertas ao uso turístico no país. Veríssimo et al. (2003) monitoraram durante seis meses a temperatura $e$ a umidade do ar de uma caverna em Ubajara, no Ceará, região do nordeste brasileiro, onde realizaram análises preliminares da capacidade de suporte da gruta para as atividades de espeleoturismo.

Mais recentemente, trabalhos de curta duração, com a coleta de dados variando entre dois a sete dias, foram realizados em cavernas brasileiras na região sudeste (Longhitano et al., 2007; Travassos, 2010; Rocha \& Galvani, 2011) e na região norte (Nascimento \& Molinari, 2012). Esses estudos tiveram como objetivo a caracterização preliminar do microclima das cavernas analisadas, além de avaliar os impactos em decorrência da sua visitação $e$, em alguns casos, compreender o zoneamento climático interno.

Todas essas pesquisas trouxeram em suas conclusões a indicação da necessidade de monitoramento de longo prazo para a melhor compreensão da dinâmica climática das cavernas, principalmente devido aos possíveis efeitos de sazonalidade. Neste contexto, chama a atenção uma das poucas pesquisas nacionais a utilizar coleta de dados em um período mais extenso (três anos), realizada na Gruta de Santana, no estado de São Paulo, por Lobo et al. (2015). Os resultados dessa pesquisa permitiram melhorar o conhecimento da dinâmica atmosférica da caverna e o aprimoramento dos critérios a serem considerados na definição da capacidade de carga.

Embora não se tratasse de uma atividade de monitoramento microclimático, os primeiros registros de coleta de dados referentes aos parâmetros meteorológicos das cavernas do Parque Nacional Cavernas do Peruaçu (PNCP) foram realizados anteriormente à criação do parque, em meados da década de 70 (Coura \& Hashizume, 1975; Silva, 1975). Nesses registros são apresentados os dados de temperatura $e$ umidade do ar coletados de forma pontual em bases topográficas oriundas do mapeamento das cavernas conhecidas como Lapa dos Desenhos, Lapa do Índio e Lapa Bonita.

A importância de se conhecer o microclima das cavidades do PNCP está refletida no escopo das ações de pesquisa e de monitoramento determinadas no plano de manejo da unidade de conservação (UC). Este documento determina que sejam monitorados os impactos ambientais causados pela visitação pública, orientando a realização de medições de temperatura $e$ umidade relativa do ar nas cavernas visitadas (IBAMA, 2005), entretanto, até o momento esta atividade não foi efetivamente implementada pela gestão da UC.

$\mathrm{O}$ atendimento a essa orientação vem se mostrando cada vez mais necessário nos últimos anos, pois, segundo informações da equipe responsável pela gestão da UC, a implantação da infraestrutura de acesso aos atrativos e o aprimoramento dos procedimentos adotados para o desenvolvimento do turismo na unidade tem contribuído para o aumento no número de visitantes. Esta pesquisa tem como objetivo realizar o monitoramento microclimático de sete cavernas integrantes do roteiro turístico do PNCP entre os anos de 2017 a 2019. A análise dos resultados permite uma melhor compreensão do comportamento climático de cada caverna, que poderá subsidiar o estabelecimento dos princípios metodológicos a serem empregados na definição do programa de monitoramento conforme preconizado pelo plano de manejo do PNCP.

Espera-se que, ao término deste trabalho, a gestão do parque tenha um produto que ofereça subsídios relativos às características do microclima que possam contribuir para redefinição da 
capacidade da carga e dos limites das áreas internas das cavernas a serem acessadas pelos visitantes. Além disso, espera-se também que possam ser oferecidos subsídios para aprimorar o conhecimento sobre a dinâmica climática de cavernas em ambientes tropicais, especialmente aquelas abertas ao uso turístico.

\section{Material e Métodos \\ Área de estudo}

O PNCP foi criado ao final da década de 90 (Brasil, 1999) como uma unidade de conservação federal de proteção integral. Está localizado na região sudeste do Brasil e o objetivo de sua criação é a preservação dos ecossistemas naturais inseridos no Vale Cárstico do Rio Peruaçu. A UC situa-se na porção norte do estado de Minas Gerais (Figura 1) e abriga algumas das mais importantes cavernas turísticas do país.

O contexto geológico da região onde está inserido o parque nacional é caracterizado basicamente por rochas carbonáticas do Grupo Bambuí, depositadas no período Neoproterozóico. Tais rochas encontram-se parcialmente cobertas na região do parque por rochas siliciclásticas do período Mesozóico Superior, pertencentes à Formação Urucuia (Schobbenhaus \& Neves,
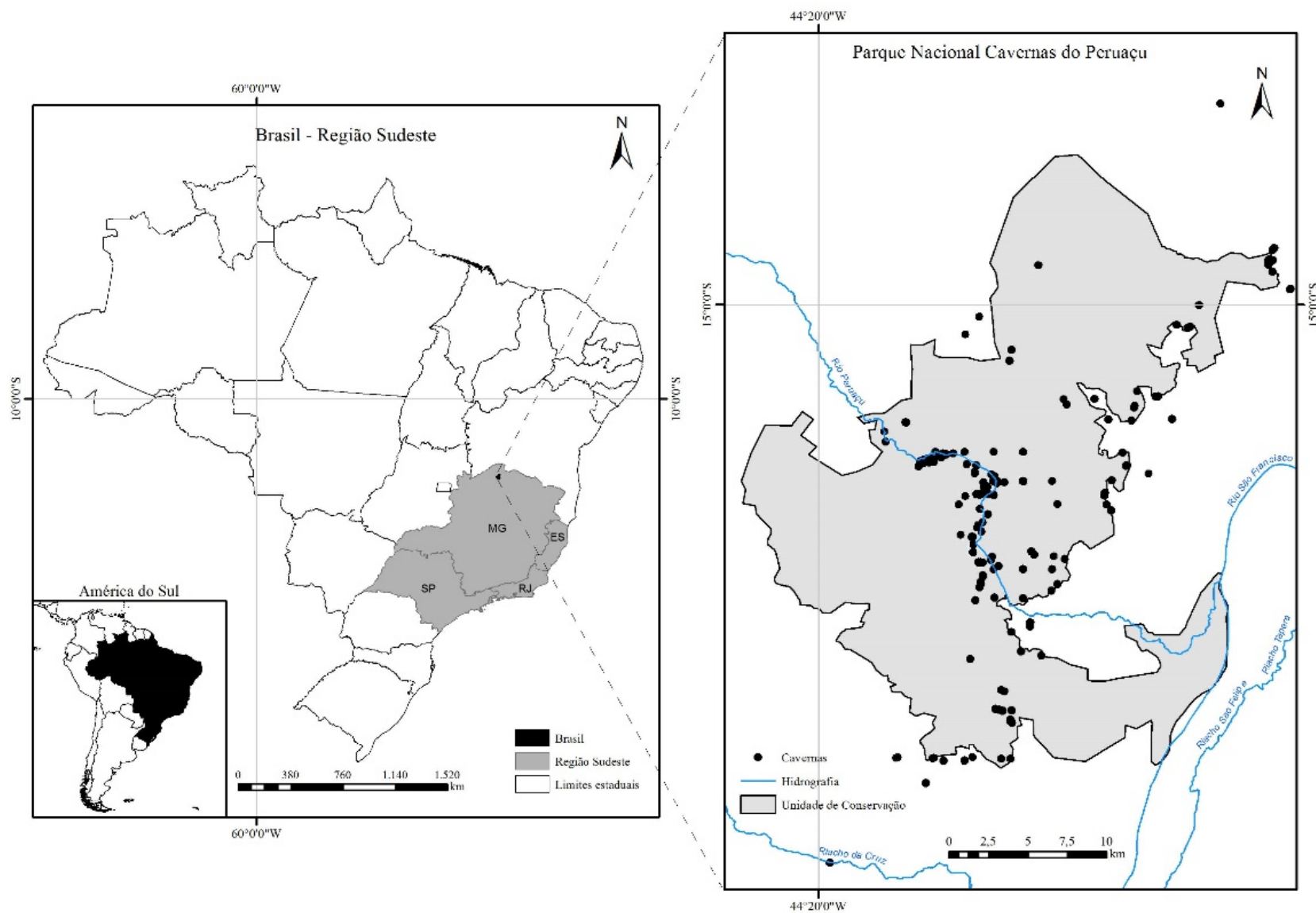

Figura 1 - Localização do Parque Nacional Cavernas do Peruaçu no estado de Minas Gerais, região Sudeste do Brasil. Fonte: Autores.

2003). Durante o Terciário, a região passou por soerguimento tectônico $e$, paralelamente, iniciouse o desenvolvimento de ampla rede de condutos subterrâneos em decorrência da circulação de água do aquífero cárstico. E, por fim, durante o período Quaternário, a evolução do relevo cárstico levou ao desabamento de diversos segmentos de tetos das cavernas culminando com a abertura do vale cárstico do rio Peruaçu (Kohler et al., 1989; Piló, 1989; Moura, 1997). 
O parque apresenta altitudes que variam de 440 a 830m na depressão do rio São Francisco e no planalto, respectivamente. Piló (1989) identificou três unidades fisiográficas homogêneas na bacia do rio Peruaçu: compartimento de Cimeira, que fica situado nos arenitos da formação Urucuia, do período Cretáceo Superior e com cotas acima de 750 metros. Já entre as cotas de 500 a 750 metros ocorrem o compartimento Carstificado, que foram desenvolvidos nos dolomitos e calcários do Grupo Bambuí. E por fim, o compartimento da depressão do São Francisco, que é constituído de coberturas inconsolidadas do período Cenozóico.

O parque fica localizado na transição entre dois importantes biomas brasileiros, a Caatinga e o Cerrado, possuindo assim, elevada biodiversidade e alto grau de endemismo. O PNCP está situado na zona climática Aw (clima tropical com inverno seco), conforme a classificação climática KöppenGeiger, (Peel et al., 2007) e possui precipitação média anual de $1.000 \mathrm{~mm}$ com as chuvas concentradas entre os meses de novembro a março (Hijmans et al., 2005)
Atualmente são conhecidas pouco mais de 150 cavernas no PNCP e o circuito turístico da unidade estudada contempla onze delas que podem ser acessadas por meio de trilhas, passarelas, mirantes e pontes implantadas recentemente. $\mathrm{O}$ patrimônio espeleológico, paisagístico, cultural, arqueológico e paleontológico encontrado na UC é um dos mais representativos do país, sendo reconhecido internacionalmente e credenciaram a unidade a se candidatar ao título de patrimônio cultural da humanidade pela Organização das Nações Unidas para a Educação, a Ciência e a Cultura (UNESCO) (IBAMA, 2005).

\section{Monitoramento microclimático}

Os parâmetros meteorológicos monitorados $e$ avaliados nas cavernas do PNCP foram: a temperatura e a umidade relativa do ar e, para isto, foram instalados 41 termo-higrômetros automatizados no interior das cavernas escolhidas para a realização deste estudo (Tabela 1).

Tabela 1 - Cavernas monitoradas que integram o circuito turístico do Parque Nacional Cavernas do Peruaçu.

\begin{tabular}{|c|c|c|c|c|}
\hline Caverna & Latitude/longitude & Altitude (m) & $\begin{array}{c}\text { Projeção } \\
\text { horizontal (m) }\end{array}$ & Instrumentos \\
\hline Lapa do Caboclo & $-15,0895^{\circ} \mathrm{S} /-44,2680^{\circ} \mathrm{W}$ & 698 & 100 & 4 \\
\hline Gruta do Janelão & $-15,1161^{\circ} \mathrm{S} /-44,2416^{\circ} \mathrm{W}$ & 686 & 4.740 & 4 \\
\hline Lapa do Índio & $-15,1079^{\circ} \mathrm{S} /-44,2437^{\circ} \mathrm{W}$ & 678 & 150 & 6 \\
\hline Lapa do Carlúcio & $-15,0847^{\circ} \mathrm{S} /-44,2626^{\circ} \mathrm{W}$ & 677 & 160 & 6 \\
\hline Lapa do Rezar & $-15,1435^{\circ} \mathrm{S} /-44,2346^{\circ} \mathrm{W}$ & 639 & 380 & 6 \\
\hline Lapa Bonita & $-15,1076^{\circ} \mathrm{S} /-44,2409^{\circ} \mathrm{W}$ & 638 & 420 & 9 \\
\hline Lapa dos Desenhos & $-15,1082^{\circ} \mathrm{S} /-44,2337^{\circ} \mathrm{W}$ & 619 & 140 & 6 \\
\hline
\end{tabular}

Fonte: Dados da pesquisa e IBAMA (2005)

Foram selecionadas sete cavernas que integram o circuito turístico, sendo contempladas nesta seleção tanto aquelas que recebem visitantes em seu interior (Gruta do Janelão, Lapa Bonita, Lapa do Carlúcio e Lapa do Rezar), quanto às cavernas onde os turistas acessam somente a parte externa do atrativo (Lapa do Índio, Lapa dos Desenhos e Lapa do Caboclo) (Figura 2A).

Para medição destes parâmetros foram instalados 41 termo-higrômetros, modelo 175-H2 do fabricante Testo (resolução: $0,1^{\circ} \mathrm{C}$ para temperatura e $0,1 \%$ para umidade relativa; acurácia: $0,1^{\circ} \mathrm{C}$ para temperatura e $0,3 \%$ para umidade relativa) $e$ cada um foi configurado para realizar a leitura e o registo de dados a cada 10 minutos.

A distribuição dos equipamentos foi feita na tentativa de se obter as leituras de temperatura e umidade relativa do ar nos diferentes ambientes encontrados no interior das cavernas, desde sua entrada até a parte mais distal (Figura 2B). 
Os termo-higrômetros ficaram instalados a uma altura média de $1,5 \mathrm{~m}$ em relação ao nível solo, utilizando-se cabos de aço e clips de fixação, evitando assim a necessidade de realização de furos na estrutura da caverna.
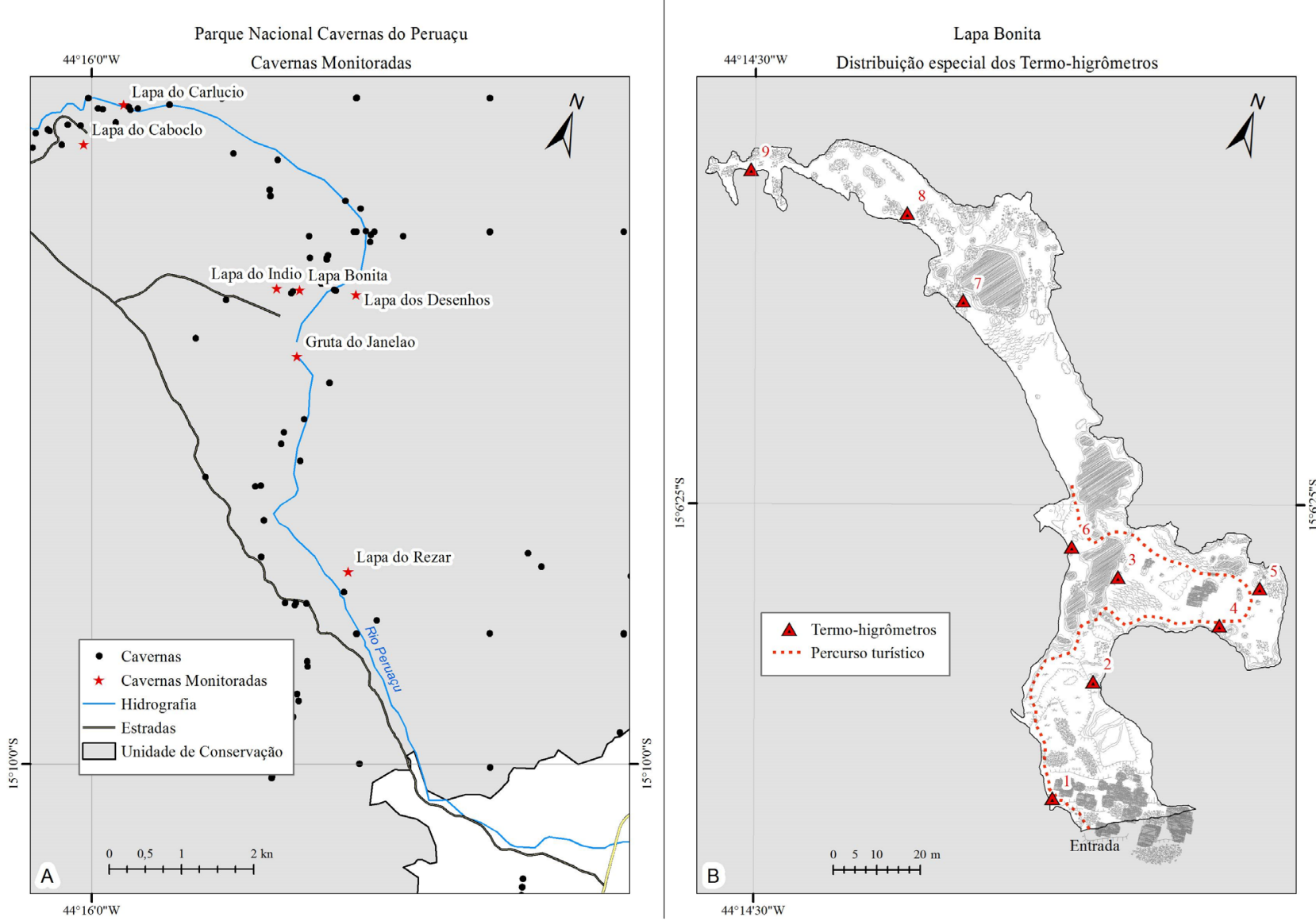

Figura 2 - A) Localização das cavernas monitoradas; e B) Localização dos termo-higrômetros instalados na Lapa Bonita e percurso de visitação interno. Fonte: Autores.

Para as cavernas que recebem visitação em seu interior, como é o caso da Lapa Bonita (Figura 2B), os medidores foram preferencialmente instalados em locais próximos às trilhas que compõem o percurso turístico com o objetivo de registrar as possíveis alterações provocadas pela presença dos visitantes.

Foram realizadas análises considerando os valores mínimos, médios e máximos da temperatura e umidade relativa do ar, bem como o desvio padrão e a amplitude dos valores de cada caverna.

\section{Resultados e Discussão}

A caverna Lapa Bonita apresentou a menor temperatura média $\left(20,79^{\circ} \mathrm{C}\right)$ considerando os registros dos termo-higrômetros instalados em seu interior, enquanto a Lapa dos Desenhos registrou a maior temperatura média $\left(24,07^{\circ} \mathrm{C}\right)$ (Tabela 2$)$.

A temperatura mínima foi registrada pelo termo-higrômetro situado na entrada da Lapa do Carlúcio $\left(9,50^{\circ} \mathrm{C}\right)$, no dia $14 / 07 / 2019$ às $06: 50$, enquanto a maior temperatura foi registrada pelo equipamento localizado no fundo da Dolina dos Macacos, interior da Gruta do Janelão $\left(39,00^{\circ} \mathrm{C}\right)$ no dia 07/10/2018 às 15:20. No período estudado, a entrada da Lapa do Carlúcio foi o local que registrou a menor temperatura média $\left(20,70^{\circ} \mathrm{C}\right)$ e a Lapa do Rezar, a maior temperatura média $\left(24,30^{\circ} \mathrm{C}\right)$ dentre todas as entradas.

Em estudos realizados em cavernas de países de clima temperado, Badino (2004) e Stoeva \& Stoev (2005) chamam a atenção para a 
Tabela 2 - Valores Mínimos, Máximos e Médios da temperatura do ar registrados, considerando o conjunto de termo-higrômetros internos de cada caverna monitorada e valores Mínimos, Médios e Máximos apenas dos instrumentos instalados nas entradas.

\begin{tabular}{|l|c|c|c|c|c|c|c|}
\hline \multicolumn{1}{|c|}{$\left({ }^{\circ} \mathbf{C}\right)$} & Bonita & Caboclo & Carlúcio & Desenhos & Índio & Janelão & Rezar \\
\hline Mínima & 12,80 & 13,60 & 9,50 & 13,80 & 12,30 & 11,50 & 13,90 \\
\hline Média & 20,79 & 23,61 & 21,12 & 24,07 & 22,29 & 22,19 & 24,01 \\
\hline Máxima & 28,10 & 28,30 & 29,50 & 29,50 & 33,70 & 39,00 & 35,40 \\
\hline Desvio padrão & 0,54 & 1,26 & 2,07 & 1,28 & 0,81 & 2,15 & 1,28 \\
\hline Amplitude & 6,34 & 9,48 & 14,35 & 8,92 & 6,70 & 17,20 & 9,10 \\
\hline Mínima (entrada) & 13,20 & 13,60 & 9,50 & 13,80 & 12,30 & 11,50 & 13,90 \\
\hline Média (entrada) & 21,52 & 22,92 & 20,70 & 23,00 & 23,72 & 22,13 & 24,30 \\
\hline Máxima (entrada) & 28,10 & 26,80 & 29,50 & 28,00 & 33,70 & 29,00 & 35,40 \\
\hline
\end{tabular}

Fonte: Dados da pesquisa.

influência que a condição climática externa exerce sobre o microclima cavernícola. No PNCP, situado em uma zona de clima topical (Peel et al., 2007), este efeito também foi observado, sendo possível perceber a relação entre a temperatura média da entrada com a temperatura média da caverna. Neste contexto, pode ser destacada a condição observada na Lapa do Carlúcio, onde se verificou o menor registro de temperatura média dentre todas as entradas $\left(20,70^{\circ} \mathrm{C}\right)$ e uma das menores temperaturas médias dentre todas as cavernas $\left(21,12^{\circ} \mathrm{C}\right)$.

Em relação à amplitude das temperaturas, destaca-se a Gruta do Janelão com o maior valor $(17,20)$. Esta caverna é caracterizada por ser um ambiente de grande circulação de energia devido à presença do rio Peruaçu e das grandes claraboias e, portanto, mais propenso às grandes variações deste parâmetro quando comparada às demais cavernas. Em situação oposta, se encontram a Lapa Bonita $(6,34)$ e a Lapa do Índio $(6,70)$ que em função da sua morfologia podem ser considerados ambientes de baixa circulação de energia e mais homogêneos em relação às variações de temperatura.

Entretanto, apesar das condições externas serem consideradas como o principal fator a influenciar o microclima cavernícola, as características intrínsecas de cada caverna também exercem um papel determinante na compreensão dos dados encontrados neste tipo de estudo, conforme destacado por Travassos (2016). Neste aspecto chamam a atenção os dados da Lapa Bonita, que registrou a menor temperatura média dentre todas as cavernas $\left(20,79^{\circ} \mathrm{C}\right)$, mas que não apresentou a menor temperatura média em sua entrada $\left(21,52^{\circ} \mathrm{C}\right)$. Juntamente com a Lapa do Carlúcio, esta caverna possui uma particularidade em sua morfologia, pois seu amplo salão de entrada possui uma forte inclinação descendente, caracterizando o local uma "armadilha de ar frio" (Lobo, 2013). Logo após este trecho existe uma pequena inclinação ascendente onde se observa um estreitamento do conduto que leva ao restante da caverna. Pela relevância do local em relação à medição dos parâmetros climáticos, um termohigrômetros foi instalado no ponto mais baixo deste salão onde foram registradas temperaturas médias mais baixas $\left(20,05^{\circ} \mathrm{C}\right)$ do que aquelas observadas na entrada $\left(21,52^{\circ} \mathrm{C}\right)$ da caverna. A temperatura média de $20,79^{\circ} \mathrm{C}$ da Lapa Bonita, portanto, além de receber a influência da temperatura externa, também é influenciada fortemente pela morfologia do salão de entrada.

Lobo (2012) destaca que as variações no microclima cavernícola e a circulação de ar no interior das cavernas são dependentes das dimensões e da complexidade do sistema subterrâneo e a análise dos dados desta pesquisa confirmam esta hipótese. A Lapa Bonita é a que apresenta a menor variação em torno da temperatura média, com desvio padrão igual a 0,54 . Com variação bem próxima à observada nesta caverna está a Lapa do Índio com desvio 
padrão igual a 0,81. A Gruta do Janelão é a que apresenta o maior desvio padrão $(2,07)$. A presença de uma única entrada e, principalmente, a existência de passagens muito estreitas entre o primeiro e segundo salão na Lapa Bonita $e$ do Índio ajudam a explicar a pequena variação de temperatura em relação à média ao longo da caverna, enquanto as diversas entradas, representadas principalmente pelas grandes claraboias, além da presença do Rio Peruaçu, promovem maior circulação de energia $e$, com isso, contribuem para explicar a grande variação de temperatura ao redor da média na Gruta do Janelão.

O termo-higrômetro instalado na entrada da Lapa do Carlúcio foi o equipamento que registrou a menor leitura de umidade relativa do $\operatorname{ar}(15,10 \%$, no dia $11 / 10 / 2017$ às $16: 20)$, já os maiores valores deste parâmetro, que variaram de $99,00 \%$ a $99,90 \%$, foram registrados pelos medidores localizados no fundo do último salão em todas as cavernas (Tabela 3).

Tabela 3 - Valores mínimos, máximos e médios da umidade relativa do ar registrados, considerando o conjunto de termo-higrômetros internos de cada caverna monitorada e valores mínimos, médios e máximos apenas dos equipamentos instalados nas entradas.

\begin{tabular}{|l|c|c|c|c|c|c|c|}
\hline \multicolumn{1}{|c|}{ \% } & Bonita & Caboclo & Carlúcio & Desenhos & Índio & Janelão & Rezar \\
\hline Mínima & 24,40 & 21,40 & 23,90 & 18,40 & 16,40 & 21,20 & 15,10 \\
\hline Média & 85,28 & 64,44 & 74,27 & 62,56 & 75,96 & 74,91 & 63,02 \\
\hline Máxima & 99,90 & 99,00 & 99,90 & 97,70 & 99,90 & 99,90 & 99,90 \\
\hline Desvio padrão & 9,96 & 14,59 & 14,15 & 15,21 & 13,78 & 14,24 & 15,00 \\
\hline Amplitude & 49,72 & 70,15 & 70,45 & 74,72 & 64,44 & 73,18 & 69,88 \\
\hline Mínima (entrada) & 24,40 & 24,90 & 31,00 & 21,60 & 16,40 & 23,50 & 15,10 \\
\hline Média (entrada) & 73,29 & 67,52 & 75,68 & 67,03 & 65,20 & 75,49 & 65,75 \\
\hline Máxima (entrada) & 99,90 & 99,00 & 99,90 & 97,70 & 98,40 & 99,90 & 99,90 \\
\hline
\end{tabular}

Fonte: Dados da pesquisa.

Ao observarmos os valores médios da umidade relativa do ar das cavernas e os compararmos com as leituras obtidas nas entradas, verifica-se também a influência das características morfológicas sobre este parâmetro. A Lapa Bonita e a Lapa do Índio são as únicas que possuem significativos estreitamentos de condutos ao final do primeiro salão, o que dificulta a circulação de ar entre esta seção e as demais partes das cavernas.

Nestas duas cavidades observou-se que os valores médios da umidade relativa do ar registrados na parte interna $(85,28 \%$ e $75,96 \%$, respectivamente) são superiores àquelas medições realizadas em suas entradas $(73,29 \%$ e 65,20\%, respectivamente). Faz-se necessário destacar que as demais cavernas apresentaram comportamento inverso, com a média da umidade relativa do ar interna menor do que a média das entradas. Isto se deve ao fato de que elas são formadas praticamente por um conduto único, amplo $e$ sem a presença de passagens significativamente estreitas entre seus salões.

Destaca-se que a Lapa Bonita e Lapa do Índio são aquelas que apresentaram os menores valores de desvio padrão $(9,96$ e 13,78, respectivamente). Este fator revela que estas cavidades, além de possuírem os ambientes internos mais úmidos dentre as cavernas estudadas, são também aquelas que apresentam as menores variações da umidade relativa do ar, registrando as menores amplitudes (49,72 e 64,44, respectivamente).

Ao verificarmos o comportamento microclimático nos vários ambientes das cavernas, também é possível perceber que as áreas mais distantes da entrada sofrem menor influência das oscilações externas, conforme observado por Badino (2010). Tanto a temperatura quanto a 
umidade relativa do ar não apresentam variações significativas e seus valores ficaram praticamente constantes durante todo o período. Entretanto, conforme ressaltado por Lobo (2011), é importante destacar que as cavernas não se constituírem em um sistema atmosférico estável.

Para investigar esta hipótese foi realizado um comparativo entre as temperaturas registradas pelos termo-higrômetros instalados próximo à entrada e aqueles localizados no último salão (mais distante da entrada), da Lapa Bonita, do Rezar e dos Desenhos (Figura 3). É importante destacar que a necessidade desta análise surgiu com o projeto já em andamento e por isto, os gráficos das Lapas Bonita e dos Desenhos não apresentam os dados iniciais em função dos termo-higrômetros terem sido instalados no salão de entrada somente no dia 27/02/2018.

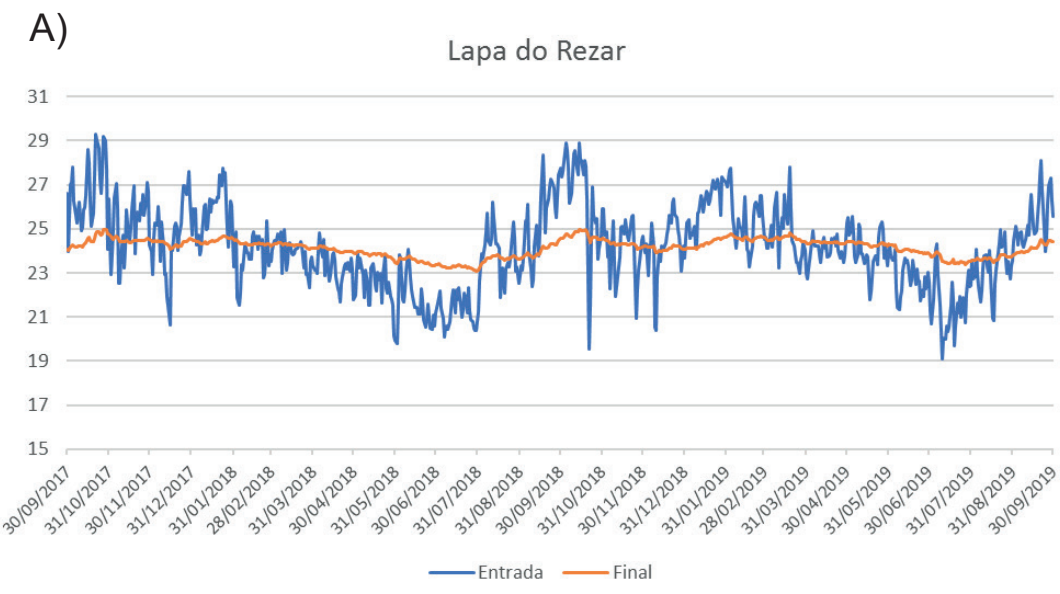

B)

Lapa dos Desenhos

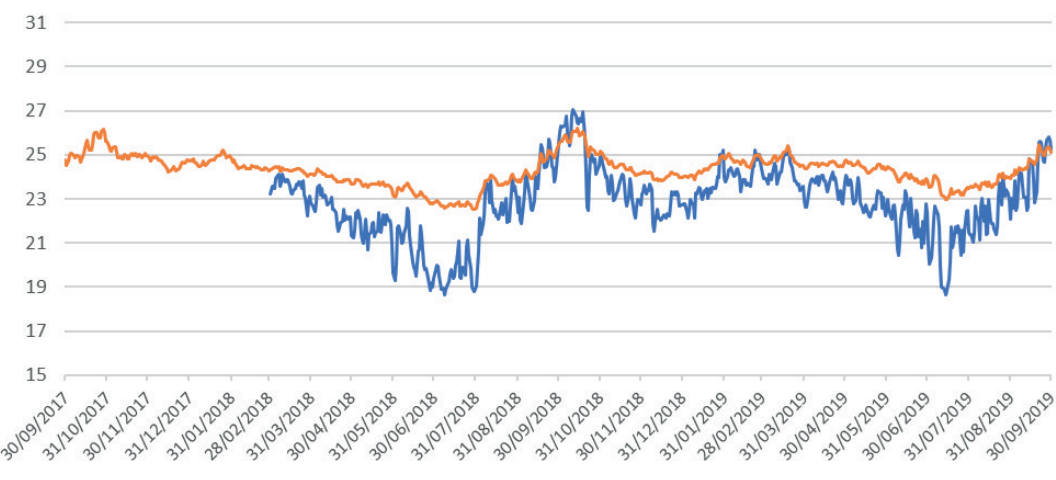

—Entrada —-Final

C)

Lapa Bonita

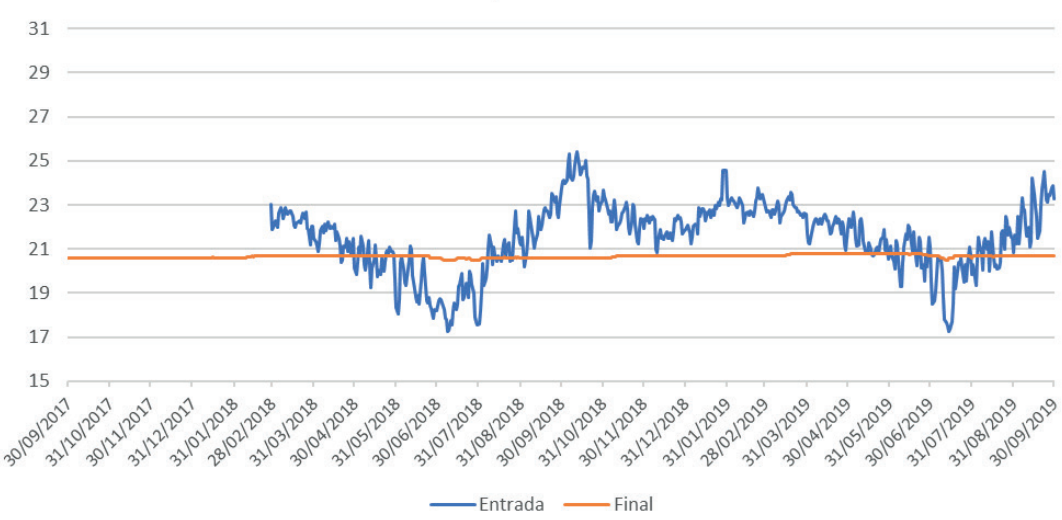

Figura 3 - Comparativo entre a temperatura média diária no salão de entrada e no último salão das cavernas. A) Lapa do Rezar; B) Lapa dos Desenhos; e C) Lapa Bonita. Fonte: Dados da pesquisa. 
Nesses gráficos é possível notar que o salão de entrada tem grande influência das variações da temperatura externa, ficando evidente a amplitude térmica provocada pela variação dia/noite e o efeito da sazonalidade durante o ano. À medida que se distancia da entrada estes efeitos são atenuados, apresentando variações menores (Lobo et al., 2014). No caso da Lapa Bonita observa-se que a temperatura se mantém praticamente constante na faixa dos $20,7^{\circ} \mathrm{C}$ (Figura 3) e apesar da entrada de grandes dimensões (Figura 4A), a passagem estreita entre o primeiro e o segundo salão (Figura 4B) e a extensão da caverna (420m de projeção horizontal) são os principais fatores responsáveis pelas discretas variações na temperatura do último salão.
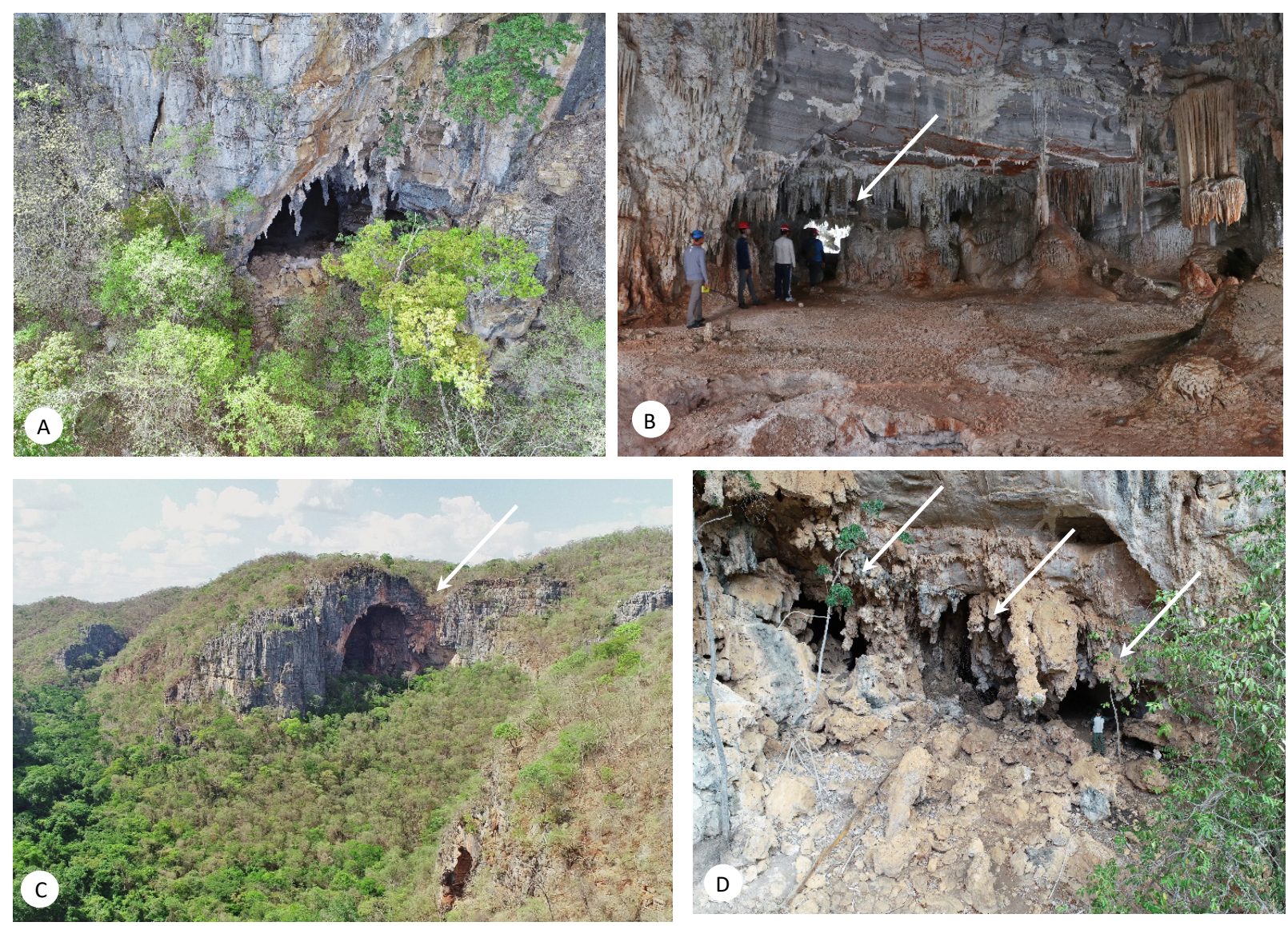

Figura 4 - Aspectos externos e internos das cavernas. A) Entrada da Lapa Bonita; B) Estreitamento do conduto entre o salão de entrada e o segundo salão da Lapa Bonita; C) Entrada da Lapa do Rezar; e D) Entrada da Lapa dos Desenhos. Fotos: Autores.

Assim como a Lapa Bonita e a Lapa dos Desenhos, a Lapa do Rezar apresenta uma única entrada (Figura 4C), porém de grandes dimensões, chegando a mais de $70 \mathrm{~m}$ de largura e 50m de altura (IBAMA, 2005). Este fator faz com que a influência externa seja percebida mais claramente no salão de entrada desta caverna, porém, por também possuir uma extensão representativa (380m de projeção horizontal) este efeito se revela mais atenuado quando se observa o comportamento da temperatura no último salão.
A Lapa dos Desenhos tem sua entrada parcialmente obstruída pela sedimentação química (Figura 4D) e o acesso à caverna é feito por intermédio de três aberturas relativamente pequenas quando comparadas com as grandes entradas das demais cavernas. Como visto anteriormente, as dimensões da entrada exercem influência na variação tanto da temperatura quanto da umidade observadas no último salão. Porém a pequena extensão da caverna $(140 \mathrm{~m}$ de projeção horizontal) contribui de maneira significativa para 
que as flutuações externas sejam percebidas com maior intensidade na parte mais distal.

\section{Conclusão}

Esta pesquisa se insere em um contexto de monitoramento de longa duração e seu objetivo está diretamente relacionado ao fornecimento de subsídios à gestão do patrimônio espeleológico explorado turisticamente no Parque Nacional Cavernas do Peruaçu. O monitoramento climático no interior das cavernas abertas à visitação está previsto no plano de manejo da UC desde 2005, entretanto não houve a sua implementação até o momento.

A metodologia utilizada para o monitoramento do microclima de cavernas empregada nesta pesquisa se mostrou efetiva $e$ atendeu aos objetivos do estudo. Acredita-se que após a realização de uma análise crítica mais refinada e os ajustes decorrentes desta etapa, a gestão do PNCP contará com um embasamento metodológico consistente para o desenvolvimento do programa de monitoramento demandado pelo plano de manejo.

Das sete cavernas que integram este estudo, quatro recebem visitantes em seu interior. Os turistas percorrem trajetos que foram definidos utilizando uma série de critérios, porém, devido à ausência de medições dos parâmetros climáticos, estas informações não foram consideradas na definição dos percursos. O monitoramento de longo prazo realizado por esta pesquisa permitirá a identificação de áreas sensíveis da caverna no que se refere às condições microclimáticas. Ao se sobrepor este "mapa de zonas sensíveis" aos mapas de risco ao visitante, de fragilidade e de estado de conservação já existentes, acreditase ser possível um aprimoramento dos trajetos internos das cavernas. A identificação das áreas sensíveis às alterações provocadas pela presença humana, definidas em função do comportamento climático predominante em cada uma delas permitirá também a realização de ajustes na quantidade de pessoas a integrarem os grupos de visitantes, ajustes no tempo de permanência em cada caverna, bem como ajustes nos tempos do intervalo entre cada grupo de turistas.

Durante o período de execução da pesquisa um novo roteiro de visitação, o Arco do André, foi inaugurado. Este novo atrativo é composto por quatro cavernas que também recebem visitantes em sua parte interna, o que vem a confirmar que o potencial de uso turístico das cavernas do PNCP é muito grande. Vale ressaltar que menos de $6 \%$ das cavernas do parque estão atualmente abertas à visitação $e$ já se discute a possiblidade de elaboração de novos roteiros incluindo outras cavernas como atrativos principais e os subsídios fornecidos por esta pesquisa poderão auxiliar o atendimento desta possível demanda, sobretudo na definição da capacidade de carga.

O aprofundamento na análise destes dados proporcionará produtos mais refinados como, por exemplo, o zoneamento climático das cavernas. A associação destes dados com os dados da visitação (número de turistas, dias e horário das visitas e o tempo de permanência no interior das cavernas) proporcionará uma caracterização mais robusta do comportamento climático das cavernas do PNCP e sua relação com o uso turístico.

O patrimônio espeleológico brasileiro, apesar de contar com mais de 20.000 cavernas conhecidas nas mais diversas litologias, é ainda pouco estudado e o seu uso para o desenvolvimento de atividades recreativas $e$ turísticas é bem incipiente. Uma parcela muito pequena deste universo de cavernas recebe turistas com regularidade e poucos são os registros de ações relacionadas ao monitoramento deste tipo de atividade. A caracterização microclimática de uma caverna e o monitoramento destas condições quando associados ao monitoramento da visitação se constituem em importantes ferramentas para a gestão das cavernas turísticas favorecendo o uso sustentável do patrimônio espeleológico.

\section{Agradecimentos}

Os autores gostariam de agradecer à equipe do Parque Nacional Cavernas do Peruaçu, por todo suporte e fornecimento de informações - em especial ao "Norinho", apoio essencial nas etapas de campo. Nossos agradecimentos também aos revisores da Revista Biodiversidade Brasileira, pelas importantes contribuições dadas ao artigo.

\section{Referências}

Aljančič M, Pipan T \& Gabrovšek F. 2016. eLTER VA Postojna Planina CS microclimate data. Data Reporting. <https://b2share.eudat.eu/records/4c9a394ef06d47e1 aa2867fb4127049f $>$. Acesso em: 22/03/2021. 
Badino G. Cave temperatures and global climatic change. International Journal of Speleology, 33: 103113, 2004.

Badino G. Underground meteorology - "What's the weather underground?" Acta Carsologica, 39(3): 427448, 2010.

Brasil. 1999. Decreto s/no, de 21 de setembro de 1999. <http://www.planalto.gov.br/ccivil 03/DNN/ Anterior\%20a\%202000/1999/Dnn8403.htm $>$. Acesso em: $11 / 01 / 2021$.

Calaforra JM, Fernández-Cortéz F, Sánchez-Martos F, Gisbert J \& Pulido-Bosch A. Environmental control for determining human impact and permanent visitor capacity in a potential show cave before tourist use. Environmental Conservation, 30(2): 160-167, 2003.

Cigna AA. Environmental management of tourist caves. Environmental Geology, 21(3): 173-180, 1993.

Coura JF \& Hashizume BR. 1975. Província espeleológica de Januária. p. 9-12. In Anais do $10^{\circ}$ Congresso Nacional de Espeleologia. Sociedade Brasileira de Espeleologia. Ouro Preto, MG. < http:// www.cavernas.org.br/anaiiscbe/10cbe_009-012.pdf $>$. Acesso em: 11/01/2021.

Hijmans RJ, Cameron SE, Parra JL, Jones PG \& Jarvis A. Very high-resolution interpolated climate surfaces for global land areas. International Journal of Climatology, 25: 1965-1978, 2005.

IBAMA. Parque Nacional Cavernas do Peruaçu - Plano de manejo. Brasília, DF: Instituto Brasileiro do Meio Ambiente e dos Recursos Naturais Renováveis, 2005.

Kohler HC, Piló LB \& Moura MTT. 1989. Aspectos geomorfológicos do Sítio Arqueológico Lapa do Boquete. 46p. In Anais do $3^{\circ}$ Congresso da ABEQUA. Rio de Janeiro, RJ.

Lobo HAS. Circulação microclimática entre superfície, grandes dolinas e cavernas no carste de São Desidério, Bahia. Sociedade \& Natureza. 25(1): 163-178, 2013.

Lobo HAS. Espeleoclima e suas aplicações no manejo do turismo de cavernas. Revista do Departamento e Geografia - USP. 23: 27-54, 2012.

Lobo HAS. 2011. Estudo da dinâmica atmosférica subterrânea na determinação da capacidade de carga turística na Caverna de Santana (PETAR, IporangaSP). Rio Claro, SP: Tese (Doutorado em Geociências e Meio Ambiente). Universidade Estadual Paulista. 392p.

Lobo HAS. Histórico das pesquisas espeleoclimáticas em cavernas brasileiras. Espeleo-Tema, 21(2): 131-144, 2010.

Lobo HAS, Boggiani P \& Berinotto J. Speleoclimate dynamics in Santana Cave (PETAR, São Paulo State, Brazil): general characterization and implications for tourist management. International Journal of Speleology, 44(1): 61-73, 2015.

Lobo HAS, Perinotto JAJ \& Boggiani PC. Monitoramento espeleoclimático do trecho turístico da Caverna Santana (Petar, SP). Mercator, 13(2): 227241, 2014.

Lobo HAS, Perinotto JAJ \& Poudou S. Análise de agrupamentos aplicada à variabilidade térmica da atmosfera subterrânea: Contribuição ao zoneamento ambiental microclimático de cavernas. Revista de Estudos Ambientais, 11(1): 22-35, 2009.

Longhitano GA, Rocha BN \& FurlanSA. Caracterização microclimática da Gruta Colorida - Parque Estadual de Intervales, SP. p. 187-193. In: Congresso Brasileiro de Espeleologia, 29, 2007. Ouro Preto, MG: Sociedade Brasileira de Espeleologia, 2007

Moura MTT. 1997. A evolução do sítio arqueológico Lapa do Boquete na paisagem cárstica do Vale do Rio Peruaçu: Januária (MG). São Paulo, SP. Dissertação (Mestrado em Geografia) Universidade de São Paulo. 220p.

Nascimento AZA \& Molinari DC. Caracterização microclimática preliminar da Gruta do Maroaga: município de Presidente Figueiredo (AM). Revista Geonorte, 2(4): 792-803, 2012.

Peel MC, Finlayson BL \& McMahon TA. Updated world map of the Köppen-Geiger climate classification, Hydrology and Earth System Sciences, 11: 1633-1644, 2007.

Piló LBA. 1989. Morfologia cárstica do baixo curso do Rio Peruaçu, Januária, Itacarambi-MG, Belo Horizonte, MG. Dissertação (Mestrado em Geografia). Universidade Federal de Minas Gerais. 80p.

Pulido-Bosch A, Martín-Rosales W, López-Chicano M, Rodríguez-Navarro CM \& Vallejos A. Human impact in a tourist karstic cave (Aracena, Spain). Environmental Geology, 31(June): 142-149, 1997.

Rocha BN \& Galvani E. Microclima de ambientes cavernícolas: Estudo de caso da Gruta da Santa, Parque Estadual de Intervales, SP. Revista Brasileira de Climatologia, 9: 21-34, 2011.

Schobbenhaus C \& Neves BBB. 2003. A geologia do Brasil no contexto da Plataforma Sul-Americana. In: BIZZI LA et al. (Eds.) Geologia, Tectônica e Recursos Minerais do Brasil. Brasília, DF: CPRM. 55p.

Šebela S, Prelovšek M \& Turk J. Impact of peak period visits on the Postojna Cave (Slovenia) microclimate. Theoretical and Applied Climatology, 111(1-2): 51-64, 2013.

Šebela S \& Turk J. Natural and anthropogenic influences on the year-round temperature dynamics of 
air and water in Postojna show cave, Slovenia. Tourism Management, 40: 233-243, 2014.

Silva LA. 1975. Relatório de excursão: Januária, MG. p. 5-8. In Anais do $10^{\circ}$ Congresso Nacional de Espeleologia. Sociedade Brasileira de Espeleologia. Ouro Preto, MG. <http://www.cavernas.org.br/anaiiscbe/10cbe_005-008. pdf > . Acesso em: 11/01/2021.

Stoeva P \& Stoev A. Cave air temperature response to climate and solar and geomagnetic activity. 76: 10421047, 2005.

Travassos LEP. 2010. A importância cultural do carste e das cavernas. Belo Horizonte, MG. Tese (Doutorado em Tratamento da Informação Espacial) - Pontifícia Universidade Católica de Minas Gerais, 372p.
Travassos LEP. 2016. Assesment of natural and atropogenic process in micrometeorology of Postojna cave system by numerical models and modern methods of data aquisition and transfer. Report (Post Doctoral Research) - Pontifícia Universidade Católica de Minas Gerais \& Research Centre of the Slovenian Academy of Sciences and Arts. Postojna. 173p.

Veríssimo CUV, Sousa AEBA, Ricardo JM, Barcelos AC, Neto JAN \& Reis MGM. 2003. Microclima e espeleoturismo na Gruta de Ubajara, CE. p. 232-240. In: Anais do $27^{\circ}$ Congresso Brasileiro de Espeleologia. Sociedade Brasileira de Espeleologia. Januária, MG. $<$ http://www.cavernas.org.br/anaiiscbe/27cbe_232-240. pdf > . Acesso em: 11/01/2021.

Biodiversidade Brasileira - BioBrasil.

Edição Temática: Análise de Componentes do Sistema Climático e a Biodiversidade no Brasil

n. 4,2021

http://www.icmbio.gov.br/revistaeletronica/index.php/BioBR

Biodiversidade Brasileira é uma publicação eletrônica científica do Instituto Chico Mendes de

Conservação da Biodiversidade (ICMBio) que tem como objetivo fomentar a discussão e a disseminação de experiências em conservação e manejo, com foco em unidades de conservação e espécies ameaçadas.

ISSN: 2236-2886 